\title{
Influence of Surface Roughness Measurement Scale on Radar Backscattering in Different Agricultural Soils
}

\author{
Alex Martinez-Agirre, Jesús Álvarez-Mozos, Hans Lievens, and Niko E. C. Verhoest
}

\begin{abstract}
Soil surface roughness strongly affects the scattering of microwaves on the soil surface and determines the backscattering coefficient $\left(\sigma^{0}\right)$ observed by radar sensors. Previous studies have shown important scale issues that compromise the measurement and parameterization of roughness especially in agricultural soils. The objective of this paper was to determine the roughness scales involved in the backscattering process over agricultural soils. With this aim, a database of 132 5-m profiles taken on agricultural soils with different tillage conditions was used. These measurements were acquired coinciding with a series of ENVISAT/ASAR observations. Roughness profiles were processed considering three different scaling issues: 1) influence of measurement range; 2) influence of low-frequency roughness components; and 3) influence of high-frequency roughness components. For each of these issues, eight different roughness parameters were computed and the following aspects were evaluated: 1) roughness parameters values; 2) correlation with $\sigma^{0}$; and 3) goodness-of-fit of the Oh model. Most parameters had a significant correlation with $\sigma^{0}$ especially the fractal dimension, the peak frequency, and the initial slope of the autocorrelation function. These parameters had higher correlations than classical parameters such as the standard deviation of surface heights or the correlation length. Very small differences were observed when longer than 1-m profiles were used as well as when small-scale roughness components $(<5 \mathrm{~cm})$ or large-scale roughness components $(>100 \mathrm{~cm})$ were disregarded. In conclusion, the medium-frequency roughness components (scale of 5-100 cm) seem to be the most influential scales in the radar backscattering process on agricultural soils.
\end{abstract}

Index Terms-Agriculture, rough surface, scattering, soil, synthetic aperture radar (SAR).

\section{INTRODUCTION}

$\mathbf{S}$ OIL surface roughness (SSR) is a variable that represents the microtopographic variations of soil surface elevations. As such, SSR greatly influences different processes at the

Manuscript received November 25, 2016; revised March 29, 2017; accepted June 3,2017. This work was supported in part by the Spanish Ministry of Economy and Competitiveness under Grant BES-2012-054521, Project CGL2011-24336, Project CGL2015-64284-C2-1-R, and Project CGL2016-75217-R (MINECO/FEDER, EU). (Corresponding author: Alex Martinez-Agirre.)

A. Martinez-Agirre and J. Álvarez-Mozos are with the Department of Projects and Rural Engineering, IS-FOOD Institute (Innovation and Sustainable Development in Food Chain), Public University of Navarre, 31006 Pamplona, Spain (e-mail: alejandro.mda@unavarra.es).

H. Lievens is with the Laboratory of Hydrology and Water Management, Ghent University, B-9000 Ghent, Belgium, and also with the Global Modeling and Assimilation Office, NASA Goddard Space Flight Center, Greenbelt, MD 20771 USA.

N. E. C. Verhoest is with the Laboratory of Hydrology and Water Management, Ghent University, B-9000 Ghent, Belgium.

Digital Object Identifier 10.1109/TGRS.2017.2717043 soil-atmosphere interface including the partition of precipitation into infiltration or runoff [1], [2], the heat and energy balance at the soil surface [3], [4], and the occurrence of windand water-driven soil erosion [5], [6]. As a result, SSR has been approached from different fields of science, addressing different research questions and using different instruments, parameters, and analysis techniques [7].

SSR-measuring instruments can be grouped into contact and noncontact devices [8]. Noncontact devices have developed rapidly in the last years and offer a cost-effective way to survey the soil surface with unprecedented resolution and data [9], [10]. However, while different instruments have large differences in performance, versatility, comfort, etc., the resulting data can be considered very similar in terms of applications [11].

Different parameters have been proposed for measuring SSR ranging from very simple indices to more complex ones [12]. The simplest ones characterize the height variations of the surface elevation records in a data set (i.e., profile, pointcloud, or digital elevation model) and are normally referred to as vertical parameters. Some other parameters measure the spatial arrangement of surface heights; that is, whether height variations occur in short or long horizontal distance, these can be referred to as horizontal parameters. To combine both properties, hybrid or combined parameters have been proposed, normally as a ratio or product of two parameters, one of each category. Finally, parameters based on the fractal geometry have also been used in the context of SSR to measure the self-similarity or self-affinity of soil surface elevations.

In synthetic aperture radar (SAR) remote sensing, the backscattered signal over bare soils, as measured through the backscattering coefficient $\left(\sigma^{0}\right)$, is influenced by a combination of factors including sensor configurations (frequency and polarization), surface characteristics [soil moisture (SM) and surface roughness], and the incidence angle of the incoming microwave pulse [13], [14]. The ability to obtain accurate SM estimations from SAR observations has received much interest from researchers across different disciplines [15]-[17]. However, for current spaceborne systems, the main sources of retrieval errors were due to issues related to the surface roughness parameterization [8], [18], [19].

Therefore, many research efforts in the SSR parameterization have focused on how to isolate its effect on SM retrieval techniques [8]. Earlier studies (see [20]), based on field radiometers and scatterometers, were conducted in different 
TABLE I

Description of the Different Roughness Classes Caused by Agricultural Treatments

\begin{tabular}{lllll}
\hline Tillage class & Acronym & Fields & Profiles & Description \\
\hline Mouldboard Plough & MP & 04 & 16 & $\begin{array}{l}\text { Tillage operation performed with a plough with multiple mouldboards at a depth of } \\
15-20 \mathrm{~cm} \text {, resulting in soil inversion and a very rough surface }\end{array}$ \\
\hline Harrowed Rough & HR & 09 & 39 & $\begin{array}{l}\text { Operation performed normally with a tine harrow to break soil clods and provide a } \\
\text { smoother surface suitable for seeding }\end{array}$ \\
\hline Harrowed Smooth & HS & 07 & 29 & $\begin{array}{l}\text { In cases where the first harrowing did not smoothen sufficiently the surface a } \\
\text { second harrowing was applied }\end{array}$ \\
\hline Planted & P & 11 & 44 & $\begin{array}{l}\text { Seeding operation performed with conventional sowing machinery, normally seed } \\
\text { drills }\end{array}$ \\
\hline Planted Compacted & PC & 01 & 04 & In few cases farmers compacted the soil surface with a roller after sowing \\
\hline
\end{tabular}

experiments to understand the role of SSR in backscatter. These data sets were also used to develop or to evaluate mathematical models (physically based or empirical based) describing the scattering of microwave pulses at the soil surface [13], [21]-[23]. These models were later numerically inverted to retrieve a variable of interest (mostly SM) from $\sigma^{0}$ observations, based on the previous knowledge of the other intervening variables (i.e., SSR parameters) or by making simplifying assumptions.

When backscatter models were applied to observations obtained from spaceborne platforms (SAR sensors), a problem arose related to the scale of observation (spatial resolution and wavelength) and the required roughness measurement scale [8]. Roughness parameters especially the correlation length were found to have multiscale properties, and their values appeared very sensitive to the measurement range (i.e., profile length) [24], [25]. Callens et al. [26] observed that some parameters reached equilibrium with increasing profile lengths. Other studies [24], [27], [28] defended the need for long profiles to include all roughness components present on the antenna-illuminated area (i.e., one pixel). However, this recommendation can be very difficult (if not impossible) to follow in practice because the spatial resolutions of SAR sensors range from $\sim 1$ to $\sim 1000$ m depending on the sensors' beam modes [29].

The spatial sampling of SSR measurements is also a key element. In general, it has been related to the wavelength of the SAR sensors. For example, Ulaby et al. [20] recommended a sampling interval of $\sim 1 / 10$ the wavelength of observations. Barber et al. [30] evaluated the influence of sampling interval on the SSR statistics over agricultural soils and observed that class differences were reduced as the measurement interval increased. They also recommended intervals of 15 and $5 \mathrm{~mm}$ for L- and C-bands, respectively.

These issues in SSR characterization caused some authors to use effective or optimum roughness parameters rather than real or measured ones [31], [32]. The effective roughness parameters are those obtained by the optimization or inversion of backscatter models (depending on whether SM measurements are used or not). As such, they provide a good model fit without necessarily producing realistic values of roughness parameters (i.e., not comparable to field measurements). In recent years, several studies successfully implemented the effective roughness approach [33]-[37].

Recently, Fung [38] proposed that many natural surfaces (e.g., agricultural surfaces and sea surfaces) have multiscale roughness properties, but not all their roughness scales contributed to backscatter. He proposed that only one specific roughness spectral component $\kappa=(4 \pi / \lambda) \sin \theta$ was responsible for microwave backscatter, where $\lambda$ is the incident wavelength and $\theta$ is the incidence angle. Therefore, at centimeter wavelengths (typical of existing SAR sensors), meter-size roughness components should not play a role in backscatter from multiscale surfaces [38].

The aim of this paper was to analyze the influence of surface roughness measurement scale on radar backscattering across different agricultural soils. The objective was to determine the roughness scales, which contribute to backscatter from agricultural soils and to provide some guidelines on how roughness should be characterized in these applications.

\section{MAterials}

\section{A. Test Site}

The data acquisition was carried out on the experimental watershed of La Tejería (N42 $44^{\prime} 10.6^{\prime \prime}$ and W1 $1^{\circ} 56^{\prime} 57.2^{\prime \prime}$ ) in the Spanish region of Navarre (Fig. 1). This watershed is part of the experimental agricultural watershed network of Navarre, created by the local Government of Navarre in 1993. The watershed is used to study the impact of agriculture on hydrological resources [39]. The total area of the watershed is about 169 ha with homogenous slopes of $\sim 12 \%$ and an altitude range from 496 to $649 \mathrm{~m}$. Its climate is humid subMediterranean with a mean annual temperature of $13{ }^{\circ} \mathrm{C}$ and an average annual precipitation of $\sim 700 \mathrm{~mm}$ distributed over 105 days. Ten agricultural fields were monitored (Fig. 1), and their sizes ranged from 3 to 7.3 ha.

Soils have a silty-clay texture (approximately $43 \%$ clay, $5 \%$ sand, and $52 \%$ silt) and are relatively shallow (0.5-1 m deep) except for swales where deeper soils can be found. The monitored fields were cultivated with rain-fed winter cereal crops (wheat, barley, or oats) sown at the end of October and harvested at the end of June. Soil preparation operations were performed sequentially during September and October. The different tillage operations (considered as different roughness classes) were mouldboard plough (MP), harrowed rough (HR), harrowed smooth (HS), planted (P), and planted compacted (PC) (Table I).

\section{B. Surface Roughness Data}

Surface roughness was measured using a laser profilometer with a total measurement range (profile length) of $5 \mathrm{~m}$, a resolution (sampling interval) of $5 \mathrm{~mm}$, and a vertical 


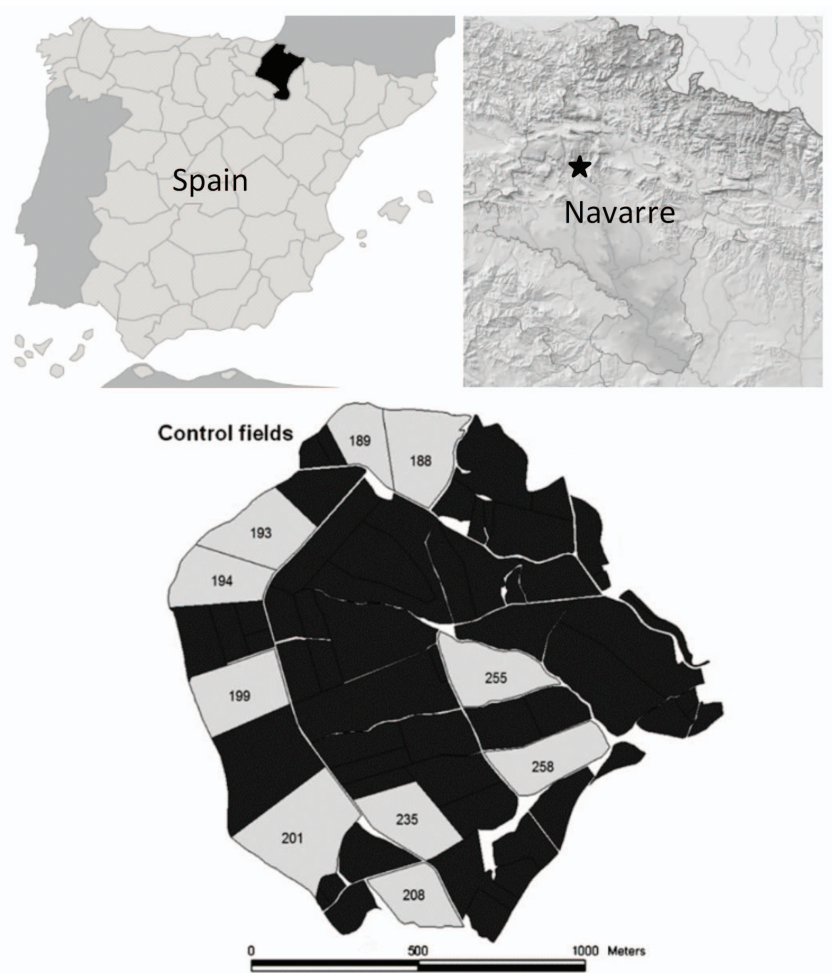

Fig. 1. Location of La Tejería experimental watershed and distribution of control fields. (Fields in black were not used in this paper.)

TABLE II

Roughness Classes CoRresponding To EACH FIELD AND Measurement Date. Four Roughness Profiles Were ACQUIRED PER FIELD, EXCEPT WHERE INDICATED

\begin{tabular}{ccccc}
\hline Field ID. & $\mathbf{2 2 / 0 9 / 2 0 0 4}$ & $\mathbf{0 8 / 1 0 / 2 0 0 4}$ & $\mathbf{2 4 / 1 0 / 2 0 0 4}$ & $\mathbf{1 7 / 1 2 / 2 0 0 4}$ \\
\hline 188 & $\mathrm{HR}^{*}$ & $\mathrm{HR}$ & - & $\mathrm{P}$ \\
189 & $\mathrm{HR}^{*}$ & $\mathrm{HR}$ & $\mathrm{HS}$ & $\mathrm{P}$ \\
193 & $\mathrm{HR}^{*}$ & $\mathrm{HR}$ & $\mathrm{P}$ & $\mathrm{P}$ \\
194 & - & $\mathrm{HR}$ & $\mathrm{HR}$ & $\mathrm{P}$ \\
199 & $\mathrm{MP}^{*}$ & $\mathrm{MP}$ & $\mathrm{MP}$ & $\mathrm{P}$ \\
201 & $\mathrm{HS}^{*}$ & $\mathrm{HS}$ & - & $\mathrm{P}$ \\
208 & MP** & - & - & $\mathrm{PC}$ \\
235 & $\mathrm{HS}$ & $\mathrm{HS}$ & $\mathrm{P}$ & $\mathrm{P}$ \\
255 & $\mathrm{HS}$ & $\mathrm{HS}$ & - & $\mathrm{P}$ \\
258 & $\mathrm{HR}$ & - & - & $\mathrm{P}$ \\
\hline
\end{tabular}

- Fields not monitored on that particular day

* Fields with 5 profiles measured

** Fields with 3 profiles measured

accuracy of $1.25 \mathrm{~mm}$ [12], [40]. Profiles $(n=132)$ were measured under bare soil conditions in parallel to the tillage direction and spatially distributed over each field, so as to obtain field average roughness parameters representative of the spatial variability within the field; in most cases, four profiles were acquired per field and date of study (Table II). For six satellite acquisition dates (Table III), the surface roughness measurements were not available and the roughness data of the previous date were considered under the assumption of no roughness change between dates. This assumption was deemed plausible because roughness smoothening due to rainfall can be considered relevant only during the first precipitation events after tillage [41], [42], which was not the case. For the time, this assumption was applied a cumulative rainfall of $103.3 \mathrm{~mm}$ had already been recorded since tillage, and besides subsequent precipitation events were weak (intensity $<2 \mathrm{~mm} / \mathrm{h}$ ).

Profiles were processed using a code developed $a d$ hoc, with the following steps:

1) correction of the buckling effect on the aluminum bar using a parabolic calibration function;

2) filtering the outliers corresponding to plant material or small holes eventually present in the soil, by deleting and linearly interpolating any records with height differences larger than a certain threshold (i.e., $2 \mathrm{~cm}$ ) with the previous and subsequent records;

3) linear correction for the terrain slope.

Further information on profile processing can be found in [12].

\section{Soil Moisture Data}

The SM of the top $10 \mathrm{~cm}$ of the soil was measured using a commercial time domain reflectometry (TDR) instrument (TRIME FM-3, IMKO $\mathrm{GmbH}$ ) connected to a portable three-rod probe. On each field, five SM-measurement locations were monitored per date, and these were spatially distributed to cover the entire field. On each location, three TDR readings were taken. The TDR probe was calibrated with in situ SM data measured with the thermogravimetric method. Here, soil samples with a known volume (necessary for the calculation of the bulk density) were also collected regularly. For four satellite acquisition dates (Table III), the TDR measurements were not available and the modeled SM values were used instead. For SM modeling, TOPMODEL-based land surface-atmosphere transfer scheme (TOPLATS) was used [43], [44] to calibrate and validate the surface SM per field using the available TDR measurements; this offered a rootmean-square error (RMSE) of $\sim 0.02 \mathrm{~cm}^{3} \cdot \mathrm{cm}^{-3}$.

\section{SAR Data}

During the study period, ten ENVISAT/ASAR scenes (C-band) were acquired over La Tejería watershed (Table III). Scenes were ordered as VV polarization precision image products in swath IS2 (incidence angles around $19^{\circ}-26^{\circ}$ ), multilooked (four looks), except for one scene (September 22, 2004) that was acquired in swath IS1 and alternate polarization (HH-VV) mode with two looks. In the latter, only the VV channel was used for consistency with the rest of data set. Half of the scenes were obtained in ascending pass, and the other half were obtained in descending pass. In all cases, the resolution was $30 \mathrm{~m} \times 30 \mathrm{~m}$. Scenes were: 1) orthorectified (with an error $<1$ pixel); 2) calibrated (using the local incidence angle); and 3) speckle filtered (gamma MAP filter with a window of $5 \times 5$ ). The digital elevation model used for preprocessing was obtained by photogrammetric techniques with a spatial resolution of $5 \mathrm{~m}$. Mean backscatter coefficient values $\left(\sigma^{0}\right)$ were calculated for each field per date.

\section{METHODS}

The analysis presented here focused on the influence of surface roughness scale on backscatter. Roughness was characterized through different parameters (explained in Section II-B) that were measured considering different scales. Here, three 
TABLE III

SUMMARY OF SAR DATA

\begin{tabular}{ccccccc}
\hline Date & SAR data & $\boldsymbol{\theta}_{\text {LOC }}\left(^{(}\right)$ & Pass & Fields & Roughness data & SM data \\
\hline $22 / 09 / 2004$ & ENVISAT/ASAR & $7.2-16.2$ & Descending & 9 & Profilometer & TDR \\
$08 / 10 / 2004$ & ENVISAT/ASAR & $11.6-20.9$ & Descending & 8 & Profilometer & TDR \\
$11 / 10 / 2004$ & ENVISAT/ASAR & $20.9-31.4$ & Ascending & 8 & $=$ & TOPLATS \\
$24 / 10 / 2004$ & ENVISAT/ASAR & $15.7-24.9$ & Descending & 5 & Profilometer & TDR \\
$27 / 10 / 2004$ & ENVISAT/ASAR & $16.9-27.2$ & Ascending & 5 & $=$ & TOPLATS \\
$17 / 12 / 2004$ & ENVISAT/ASAR & $11.6-20.9$ & Descending & 10 & Profilometer & TDR \\
$20 / 12 / 2004$ & ENVISAT/ASAR & $20.8-31.2$ & Ascending & 10 & $=$ & TOPLATS \\
$02 / 01 / 2005$ & ENVISAT/ASAR & $15.8-24.5$ & Descending & 10 & $=$ & TDR \\
$05 / 01 / 2005$ & ENVISAT/ASAR & $16.8-26.9$ & Ascending & 10 & $=$ & TDR \\
$24 / 01 / 2005$ & ENVISAT/ASAR & $20.9-31.3$ & Ascending & 10 & $=$ & TOPLATS \\
\hline
\end{tabular}

* Scene acquired in Alternative Polarization (HH-VV) Mode with 2 looks in swath IS1
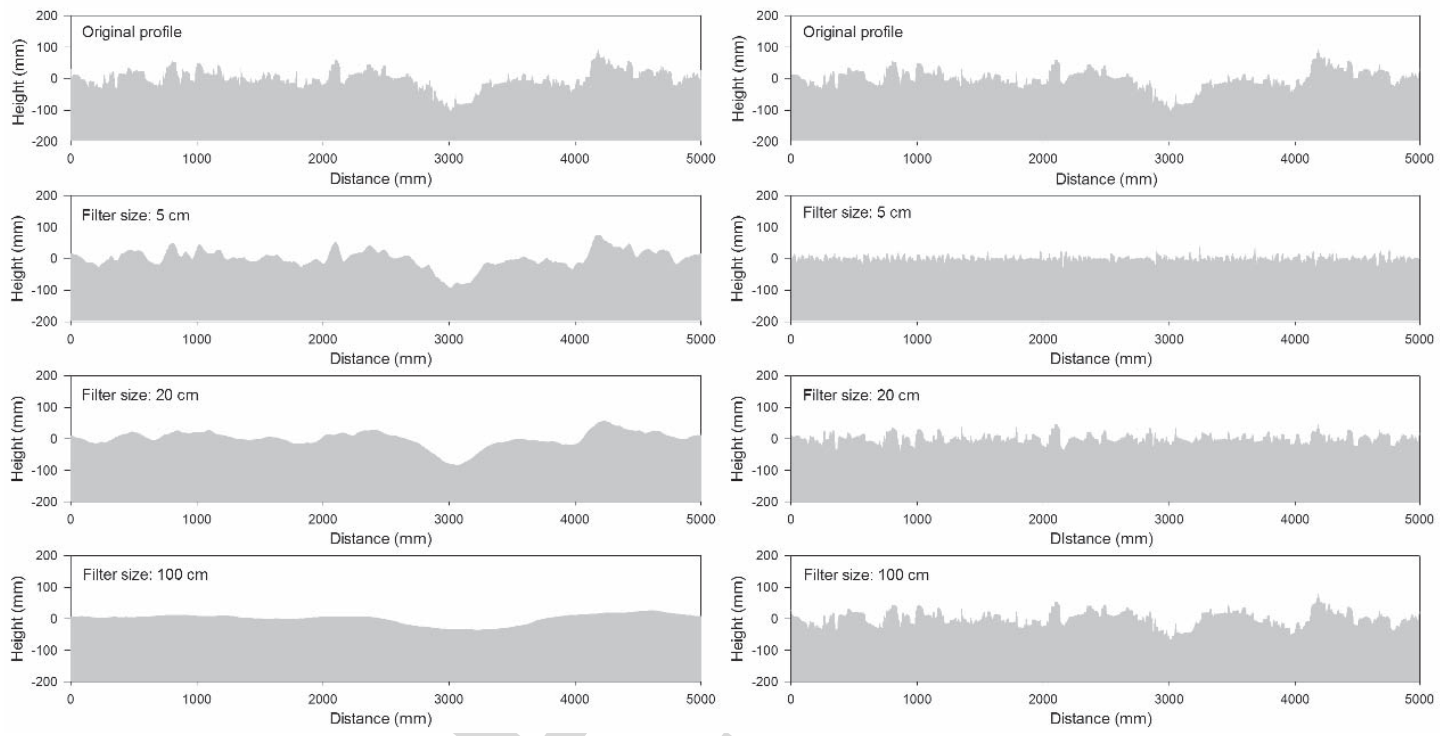

Fig. 2. Example of profile filtering. (Top) Original profile, (Left column) low-frequency roughness components, and (Right column) high-frequency roughness components for increasing filter sizes.

scaling issues were investigated: 1) the influence of measurement range (profile length); 2) the influence of low-frequency roughness components; and 3) the influence of high-frequency roughness components.

To study the influence of the measurement range, each roughness parameter was calculated with decreasing profile lengths by dividing the original profile into $2,3, \ldots, 10$ profiles of equal length, leading to profiles of 2.5-, $1.66-, \ldots, 0.5-\mathrm{m}$ length. Next, to study the low-frequency components, profiles were smoothened using moving median filters of increasing window size: $1,2,5,10,20,50$, 100 , and $200 \mathrm{~cm}$. This way, the high-frequency components of increasing wavelengths were masked from the profiles. Finally, to study the influence of high-frequency components, the smoothened profiles obtained for increasing filter sizes were subtracted from their corresponding original profiles such that only the high-frequency components remained (Fig. 2.).

For each of these three scaling issues, the following analyses were carried out: 1) assessment of the behavior of roughness parameters for the different scales investigated; 2) correlation of SAR backscatter with roughness parameters obtained at different scales; and 3) evaluation of the goodness-of-fit of ${ }_{261}$ a backscatter model parameterized with roughness parameters obtained from different scales.

\section{A. Behavior of Roughness Parameters}

In total, eight roughness parameters were analyzed (Table IV). These parameters were selected after a detailed analysis [12], where their ability to discriminate different tillage classes was assessed. Some of these parameters were descriptors of the vertical roughness component (vertical parameters), i.e., the standard deviation of surface heights $(s)$ [45] and the microrelief index (MI) [46]. Others parameters measured the horizontal component (horizontal parameters), i.e., the correlation length $(l)$ [20], the initial slope of the autocorrelation function $\left[\rho^{\prime}(0)\right][20]$, and the peak frequency $(F)$ [46]. Some parameters combined both components (combined parameters), i.e., parameter MIF [46] and the tortuosity index of Saleh $\left(T_{S}\right)$ [47]. Finally, fractal dimension $(D)[48]$ was also considered. The behavior of the different roughness parameters was evaluated by comparing 
TABLE IV

Summary OF THE ROUGHNESS PARAMETERS ANALYZED

\begin{tabular}{lllll}
\hline Type & Parameter & Description & Equations & Ref. \\
\hline Vertical & $s(\mathrm{~cm})$ & Standard deviation of surface heights & $s=\sqrt{\frac{\sum_{i=1}^{N}\left(z_{i}{ }^{2}-\bar{Z}^{2}\right)}{N-1}}$ & {$[45]$} \\
& $M I(\mathrm{~cm})$ & Microrelief index & -- & {$[46]$} \\
\hline Horizontal & $l(\mathrm{~cm})$ & Correlation length & $\rho(h)=\frac{\sum_{i=1}^{N(h)} z_{i} z_{i+h}}{\sum_{i=1}^{N} Z_{i}{ }^{2}}$ & {$[20]$} \\
& $\rho^{\prime}(0)$ & Initial slope of the auto-correlation function & --- & {$[20]$} \\
& $F\left(\mathrm{~cm}{ }^{-1}\right)$ & Peak frequency & -- & {$[46]$} \\
\hline Combined & $M I F$ & Combined parameter & $M I F=M I \cdot F$ & {$[46]$} \\
& $T_{S}$ & Tortuosity & & {$[47]$} \\
\hline Fractal & $D$ & Fractal dimension (semivariogram method) & $\gamma(h)=l^{1-H} h^{H} ; D=2-H$ & {$[48]$} \\
\hline
\end{tabular}

$s$ is the standard deviation of heights where $N$ is the number of height records, $z_{i}$ is the height of record $i$, and $\bar{z}$ is the mean height of all records. $\rho(h)$ is the autocorrelation function, the correlation length $l$ is then defined arbitrarily as the distance at which the heights of two points are considered independent; i.e., $\rho(h)$ is equal to $1 / \mathrm{e}$, so that $\rho(l)=1 / e$. Another parameter extracted from the autocorrelation function is its initial slope $\rho^{\prime}(0)$. $M I F$ is a combined parameter where $M I$ represents the area per unit length between the measured surface profile and the regression line obtained through least squares, and $F$ is the number of peaks per unit length. Tortuosity is a roughness index based on the ratio of the surface profile perimeter length $\left(L_{l}\right)$ and its horizontal projection $\left(L_{0}\right)$. Assuming a fractal Brownian motion $(f B m)$ model, the experimental semivariogram can be described as a function of the lag, where $l$ is the crossover length and $H$ is the Hurst coefficient. Afterward, $H$ was related to the fractal dimension as $D=2-H$.

the average and standard deviation of each roughness parameter per class for the different scales under study.

\section{B. Correlation of Backscatter With Roughness Parameters}

To analyze the correlation between backscatter signal and roughness parameters, a two-stage backscatter data normalization was applied to remove the influence of factors other than roughness on $\sigma^{0}$ values. First, the $\sigma^{0}$ values were normalized toward a reference incidence angle based on the generalized Lambert's law [49]

$$
\sigma_{\theta_{\mathrm{ref}}}^{0}=\sigma^{0} \frac{\cos ^{n} \theta_{\mathrm{ref}}}{\cos ^{n} \theta}
$$

with $\sigma^{0}$ being the linear backscatter observation at the incidence angle $\theta$, and $\sigma_{\theta_{\mathrm{ref}}}^{0}$ being the linear backscatter normalized to a reference incidence angle $\theta_{\text {ref }}$ set to $20^{\circ}$ (which corresponds to the average value of the observations). The exponent $n$ represents the degree of Lambertianity of the target and was therefore optimized for each roughness class minimizing the correlation between $\sigma_{\theta_{\text {ref }}}^{0}$ and the incidence angle. ( $n$ values between 2 and 8 were obtained for the different roughness classes.) A second normalization was performed to compensate $\sigma^{0}$ variations due to SM fluctuations. With this aim, a linear relation was assumed between $\sigma_{\theta_{\mathrm{ref}}}^{0}$ and SM for fields of different roughness classes observed on dates with contrasting SM conditions. The resulting linear function was used to detrend $\sigma_{\theta_{\text {ref }}}^{0}$ leading to $\sigma_{\text {norm }}^{0}$. The linear regression approach has offered good results in the past (see [50], [51]). To assess the correlation between backscatter signal and roughness parameters, the Spearman $R$ coefficient was computed between the field average $\sigma_{\text {norm }}^{0}$ and the roughness parameters obtained for each field and date.

\section{Goodness-of-Fit of Backscatter Model}

In the last part, the empirical backscatter model of Oh et al. [22] was considered. The Oh model was selected because of its ample validity range including both rough and smooth conditions and its adequate simulation of the co-polarized backscatter [52], [53]. Other models (i.e., integral equation model [21], geometrical optic model, and small perturbation model [54]) were discarded because a significant part of the measured fields was outside their validity range. Model goodness-of-fit was evaluated by computing the RMSE between simulated and observed $\sigma^{0}$ values (without backscatter data normalization). It must be mentioned that the Oh model was empirically built based on in situ data with some particular roughness conditions ( $s$ values between 0.32 and $3.02 \mathrm{~cm})$ and measurement techniques $(1-\mathrm{m}$ long profiles with a $0.25-\mathrm{cm}$ sampling interval), and this fact might have influenced the results obtained here.

\section{RESUlTS}

\section{A. Roughness Measurements Using Original Profiles}

Prior to roughness scale analysis, the results obtained with the original profiles (5-m length, 5-mm sampling interval) were analyzed. The behavior of the different roughness parameters per roughness class is shown in the boxplots (Fig. 3). The vertical parameters $s$ and MI and the combined parameter MIF presented a very similar behavior. The mean class values and class variability decreased from the roughest class to the 

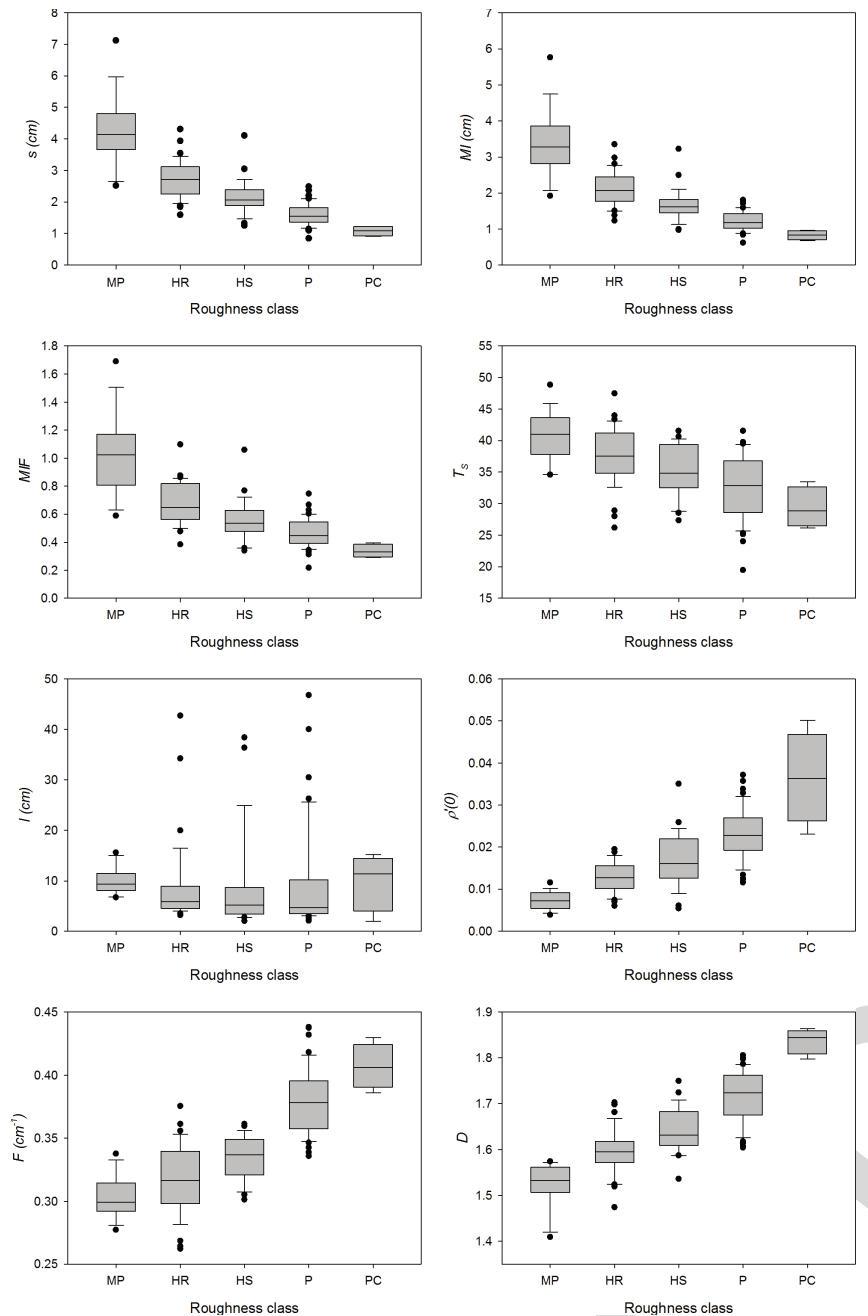

Fig. 3. Box plots of the different roughness parameter values per roughness classes. smoothest class (MP and PC, respectively). The combined parameter $T_{S}$ also showed decreasing mean class values but with similar variability in all classes. On the other hand, horizontal parameters $\rho^{\prime}(0)$ and $F$ and fractal parameter $D$ had increasing mean class values and similar variability. Finally, the horizontal parameter $l$, i.e., the correlation length, behaved completely different with no clear trends and overlapping values for the different classes.

The correlation of the normalized backscatter coefficient $\left(\sigma_{\text {norm }}^{0}\right)$ with the roughness parameters varied markedly depending on the parameter under study (Fig. 4). The fractal parameter $D(R=-0.651)$ and the horizontal parameters $F(R=-0.641)$ and $\rho^{\prime}(0)(R=-0.617)$ showed the highest correlations followed by the vertical parameters MI $(R=0.585)$ and $s(R=0.584)$. The combined parameters MIF $(R=0.528)$ and especially $T_{S}(R=0.433)$ had a lower correlation. On the other hand, the horizontal parameter $l$ had the lowest correlation $(R=0.064)$.

Regarding the goodness-of-fit of the Oh model (Fig. 5), the mean RMSE value between the simulated and observed backscatter was $1.323 \mathrm{~dB}$. The fitting for the HS roughness class (RMSE $<1 \mathrm{~dB}$ ) was very good. For the P, HR, and MP roughness classes, the RMSE values ranged from 1 to $1.5 \mathrm{~dB}$.
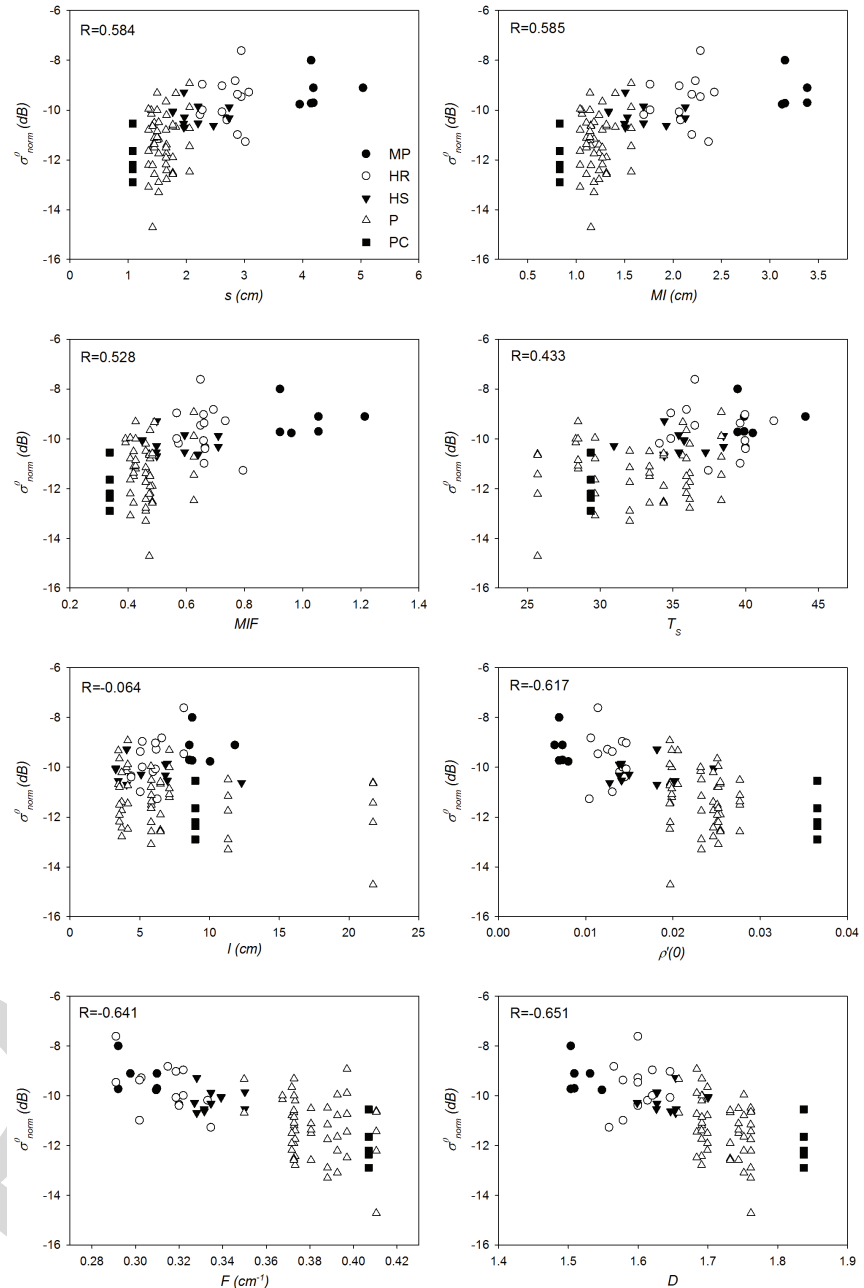

Fig. 4. Scatterplots between $\sigma_{\text {norm }}^{0}$ and the different roughness parameters by field. The Spearman correlation coefficient $(R)$ is also given.

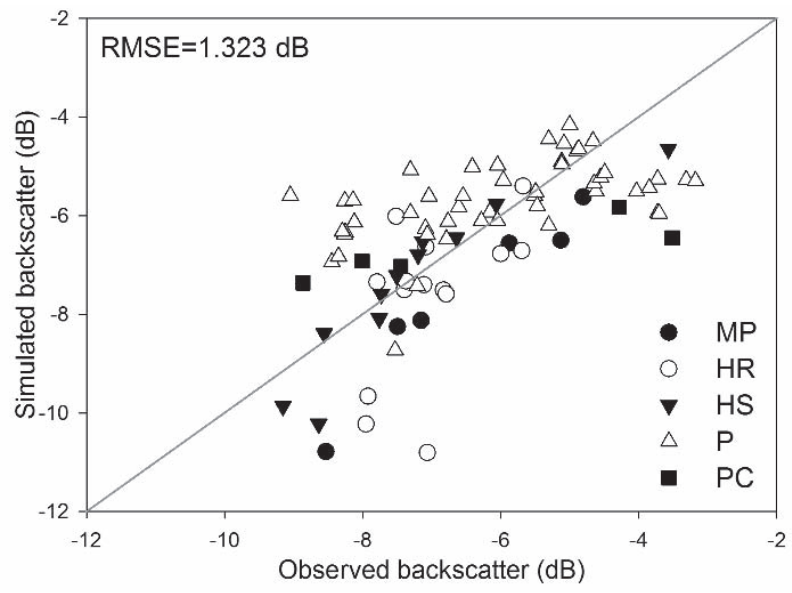

Fig. 5. Goodness-of-fit between simulated and observed backscatter coefficients per field.

Finally, for the PC roughness class (only one field at 358 different dates), the RMSE value was close to $2 \mathrm{~dB}$.

\section{B. Influence of Profile Length}

Fig. 6 depicts the behavior of the different roughness parameters per class depending on the profile length. Vertical parameters $(s$ and MI) increased with increasing profile lengths 

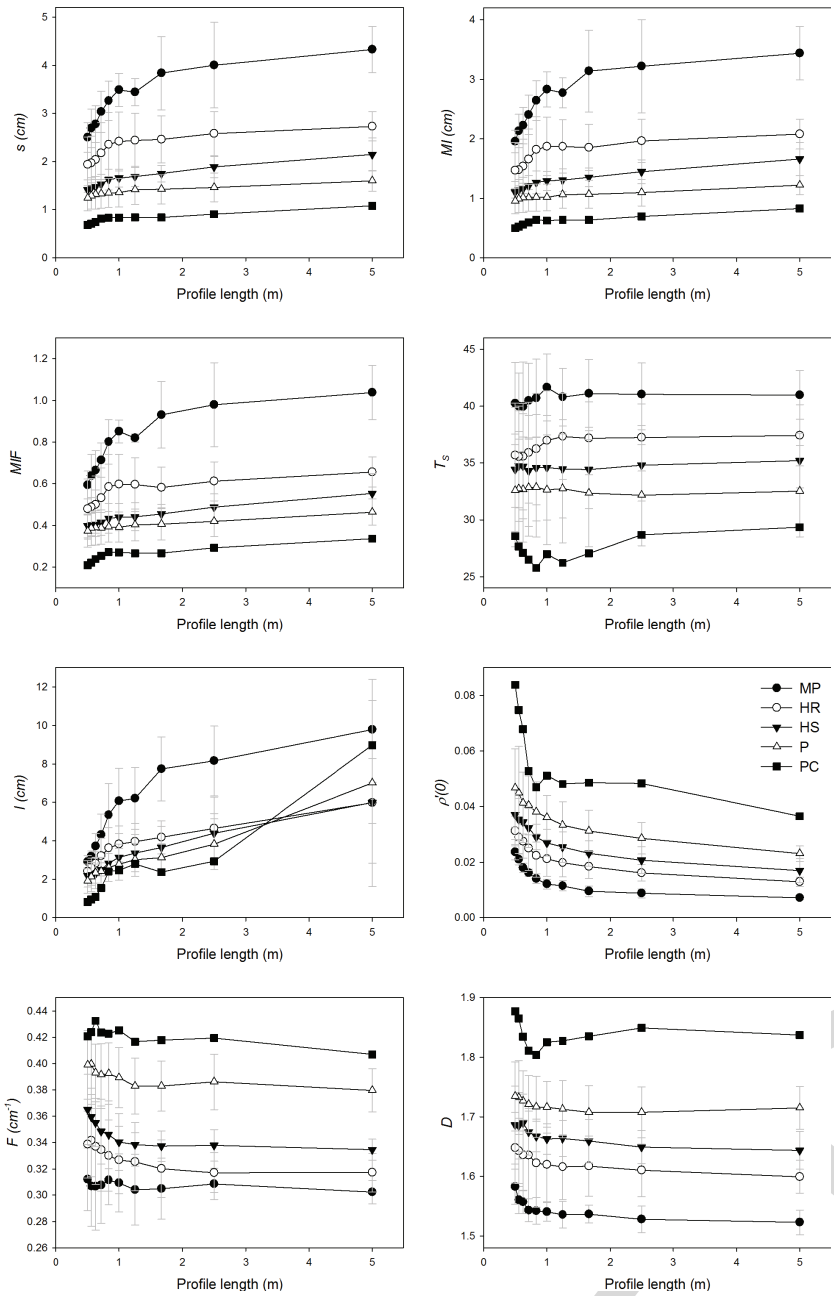

Fig. 6. Influence of profile length on roughness parameters. Mean values of roughness parameters and standard deviation (error bars) for the different roughness classes depending on the profile length. especially for rough classes (e.g., MP). The variability per class (error bars in Fig. 6) of the vertical parameters normally decreased with increasing profile lengths. Horizontal parameters did not exhibit a consistent trend, and different patterns were observed for the different parameters. For instance, parameters $\rho^{\prime}(0)$ and $F$ followed a generally decreasing trend, steeper in the shortest profile lengths and gentler at the longer profile lengths. There were some exceptions, particularly in the MP class. Furthermore, the $\rho^{\prime}(0)$ and $F$ values were quite different for the different classes regardless of the profile length. The variability per class of $\rho^{\prime}(0)$ and $F$ parameters normally decreased with increasing profile lengths, with the variability of $\rho^{\prime}(0)$ being lower than that of $F$. The parameter $l$ had different patterns and a growing trend for increasing profile lengths, although values at short profile lengths were quite erratic and variable. In this case, the variability per class seemed to increase for longer profiles. The combined parameters (MIF and $T_{S}$ ) had a similar trend as the vertical ones with slightly increasing values and decreasing class variabilities for increasing profile lengths. Finally, the fractal parameter $D$ had a trend very similar to $\rho^{\prime}(0)$ except for the MP class.
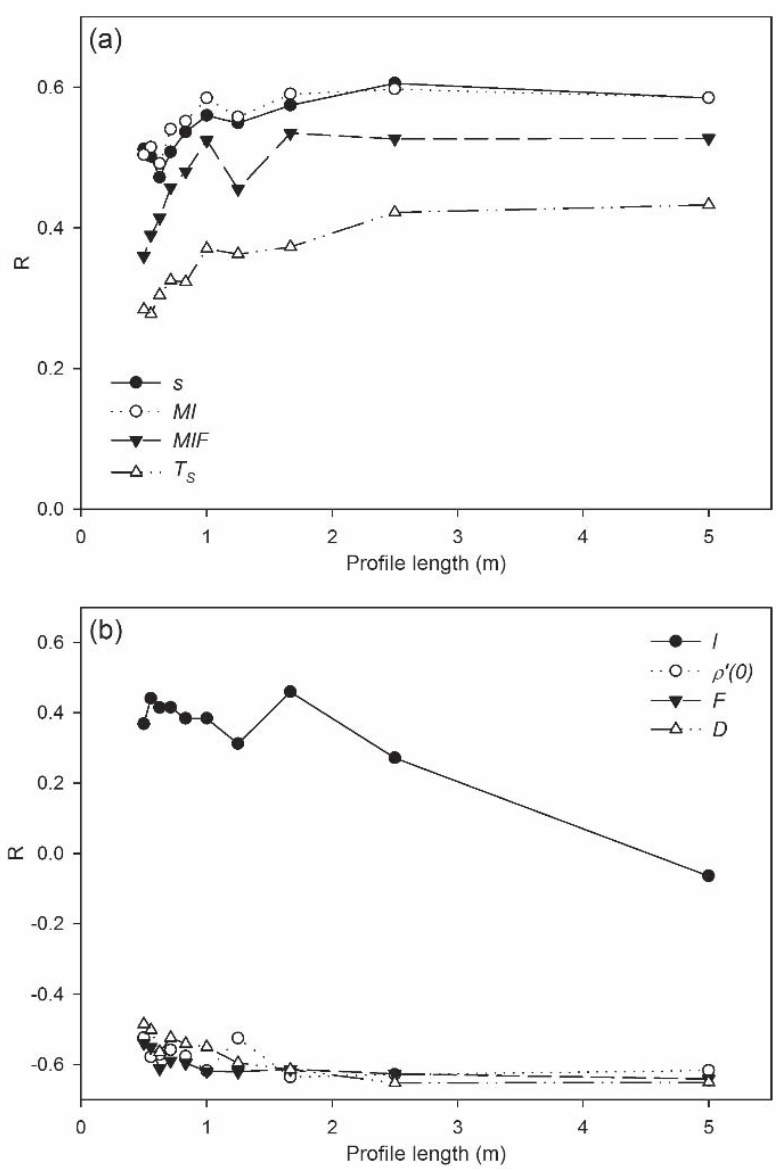

Fig. 7. Spearman's correlation coefficients $(R)$ between $\sigma_{\text {norm }}^{0}$ and the different roughness parameters depending on the profile length. (a) Vertical and combined parameters. (b) Horizontal and fractal ones.

The correlation of $\sigma_{\text {norm }}^{0}$ with the different roughness parameters depending on profile length is presented in Fig. 7. The Spearman correlation values $(R)$ are given for a more straightforward interpretation of results. Vertical parameters showed a very similar correlation trend with $R$ values ranging from 0.5 to 0.6 . These increased at short profile lengths (from 0.5 to $1 \mathrm{~m}$ ) and then stabilized for longer profiles (from 1 to $5 \mathrm{~m}$ ). Horizontal parameters did not show a consistent pattern. On one hand, $\rho^{\prime}(0)$ and $F$ behaved similar to the vertical parameters (inverse correlation) with $R$ values increasing for longer profile lengths. The $R$ values achieved by these two parameters, especially $F$, were very high $(\sim-0.6)$. This was even higher than those for vertical parameters regardless of the profile length. In contrast, $l$ had maximum $R$ values of $\sim 0.4$ with short profile lengths and very low correlations with longer profiles. The combined parameters also behaved very similar to the vertical ones, but with slightly lower correlation values. Parameter $D$ also showed an increasing trend with high $R$ values $(<-0.6)$ for profiles longer than $2-3 \mathrm{~m}$ and values dropping to $\sim-0.5$ for lengths below $1 \mathrm{~m}$.

The Oh model showed a consistent trend of decreasing RMSE values for increasing profile lengths. This was true across all of the different roughness classes (Fig. 8) with RMSE values decreasing mostly between 0.5 - and $1-\mathrm{m}$ profile lengths and then stabilizing for longer profiles. With short 


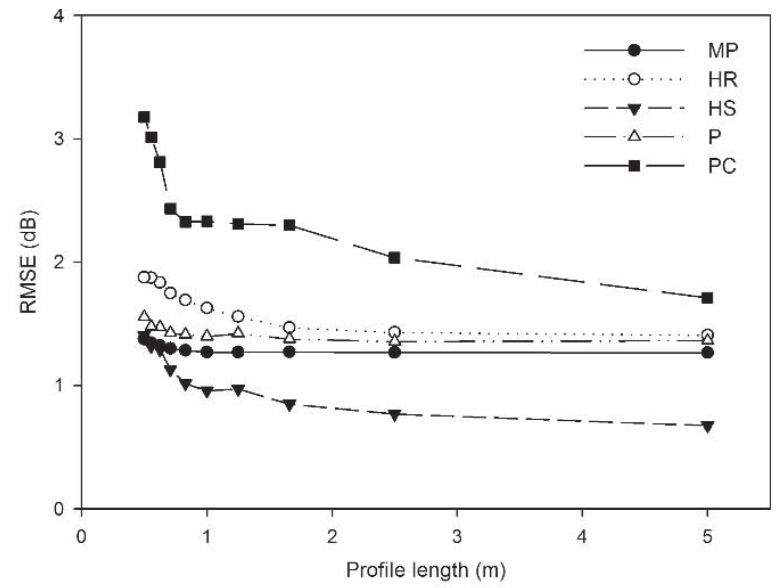

Fig. 8. Roughness class average RMSE between simulated (the Oh model) and observed field backscatter values depending on the profile length.

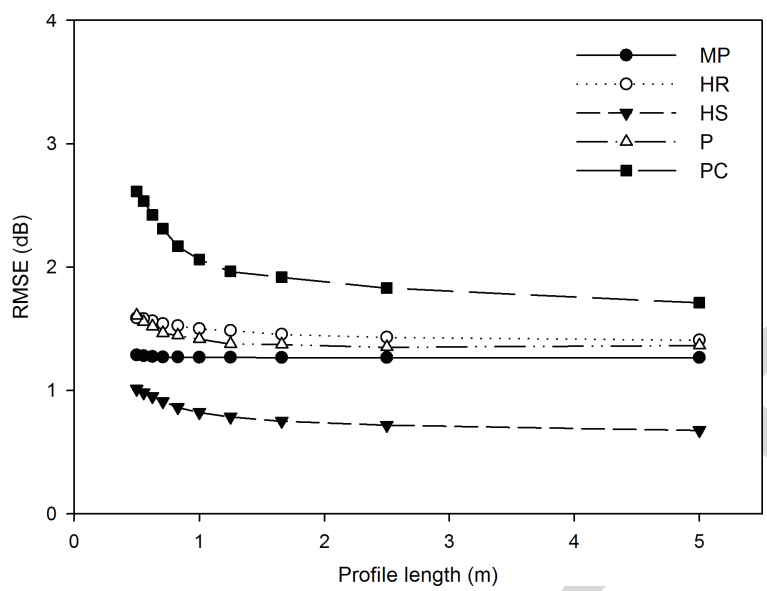

Fig. 9. Roughness class average RMSE between simulated (the Oh model) and observed field backscatter values depending on the profile length. The number of shorter profiles was increased so that the same soil surface sample was surveyed than that for longer profiles.

profiles, the errors were particularly large for class PC (the smoothest class and with only one field observed on different dates). On the other hand, the MP class showed a rather insensitive behavior with profile lengths.

The higher RMSE values observed for shorter profile lengths might be partly explained by the fact that the short profiles survey a much smaller soil surface sample than longer ones. That is, the field average roughness parameters computed using four $1-\mathrm{m}$ profiles (with a sampling interval of $5 \mathrm{~mm}$ ) are based on 800 surface height records, whereas four 5-m profiles are based on 4000 records. This sampling effect might hide the influence of different roughness scale components in Fig. 8. Therefore, Fig. 9 shows the same results but obtained by increasing the number of profiles at shorter lengths to the maximum allowed by the original 5-m length (i.e., one $5-\mathrm{m}$ profile, two $2.5-\mathrm{m}$ profiles, and four $1.25 \mathrm{-m}$ profiles). This way, different profile lengths correspond to the same soil surface sample (same number of height records) and differences are only due to the influence of different roughness scale components. This time, the influence of profile length on the Oh model fit is much lower (Fig. 9). There were only slight increases in the RMSE values for profiles shorter than $1 \mathrm{~m}$.
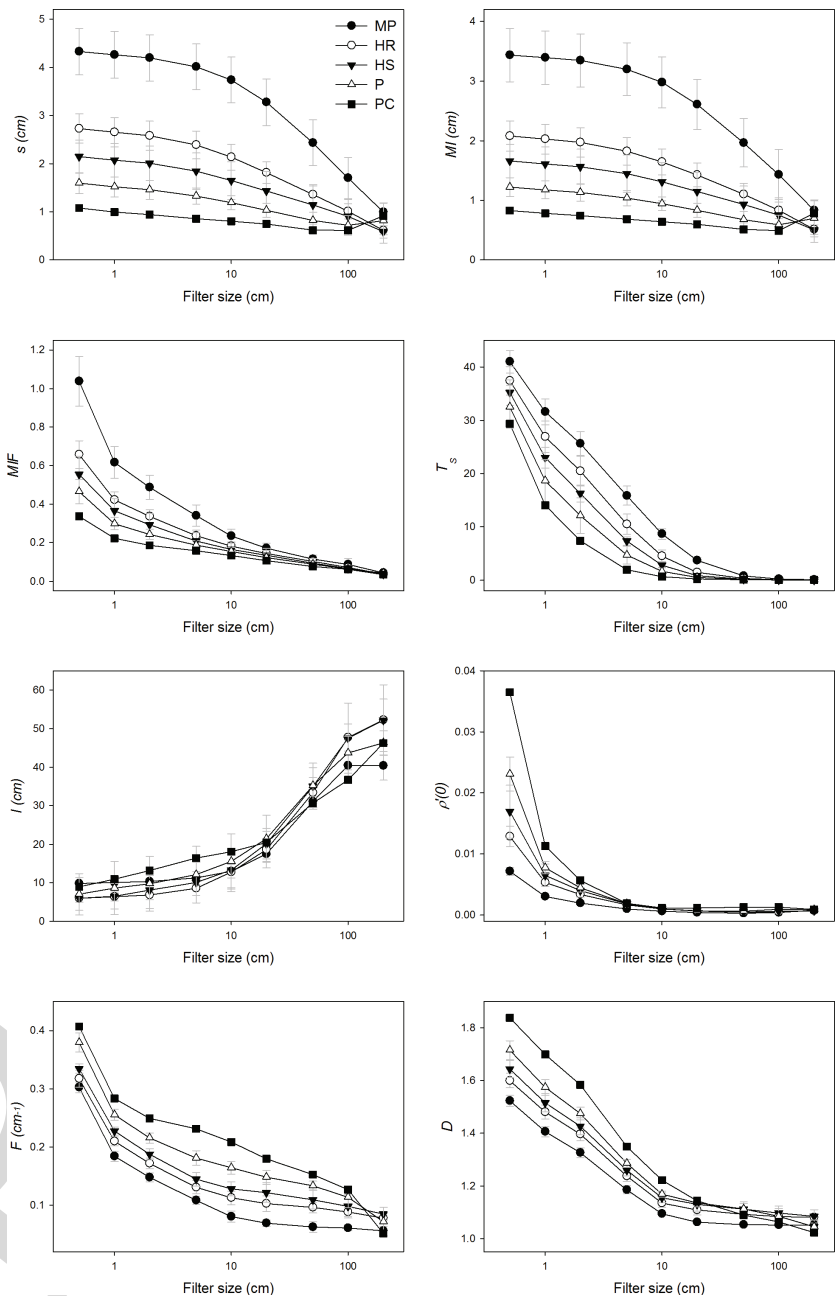

Fig. 10. Influence of profile smoothening on roughness parameters. Mean values of roughness parameters and standard deviation (error bars) for the different roughness classes for increasing a filter size. A filter size of $0.5 \mathrm{~cm}$ corresponds to original profiles.

\section{Influence of Low-Frequency Roughness Components}

Most parameters (except $l$ ) had decreasing values for all roughness classes (Fig. 10) as profiles were smoothened (i.e. short-frequency components discarded). However, this decreasing trend varied. Vertical parameters $s$ and MI decreased gently at the beginning but were steeper after a filter size of $10 \mathrm{~cm}$ (expect for PC). This indicates a higher sensitivity to larger scale components. Most horizontal, combined, and fractal parameters had an opposite trend with a strong decrease at small filter sizes and a stabilization for larger ones. This illustrates the higher influence of small-scale components on their values. The parameter $l$ showed a very unique trend (among horizontal parameters) of steady growth as the filter size increased. But then took higher increasing rates for filter size between 20 and $100 \mathrm{~cm}$. Therefore, it seems that $l$ is more strongly influenced by larger-scale components than the other horizontal parameters.

Correlation values of vertical parameters ( $s$ and MI) with $\sigma_{\text {norm }}^{0}$ slightly decreased as the profiles were smoothened until a window size of $50 \mathrm{~cm}$. It then sharply decreased until $200 \mathrm{~cm}$ (Fig. 11). Horizontal parameters did not show a unique behavior. Parameter $l$ increased in correlation as 

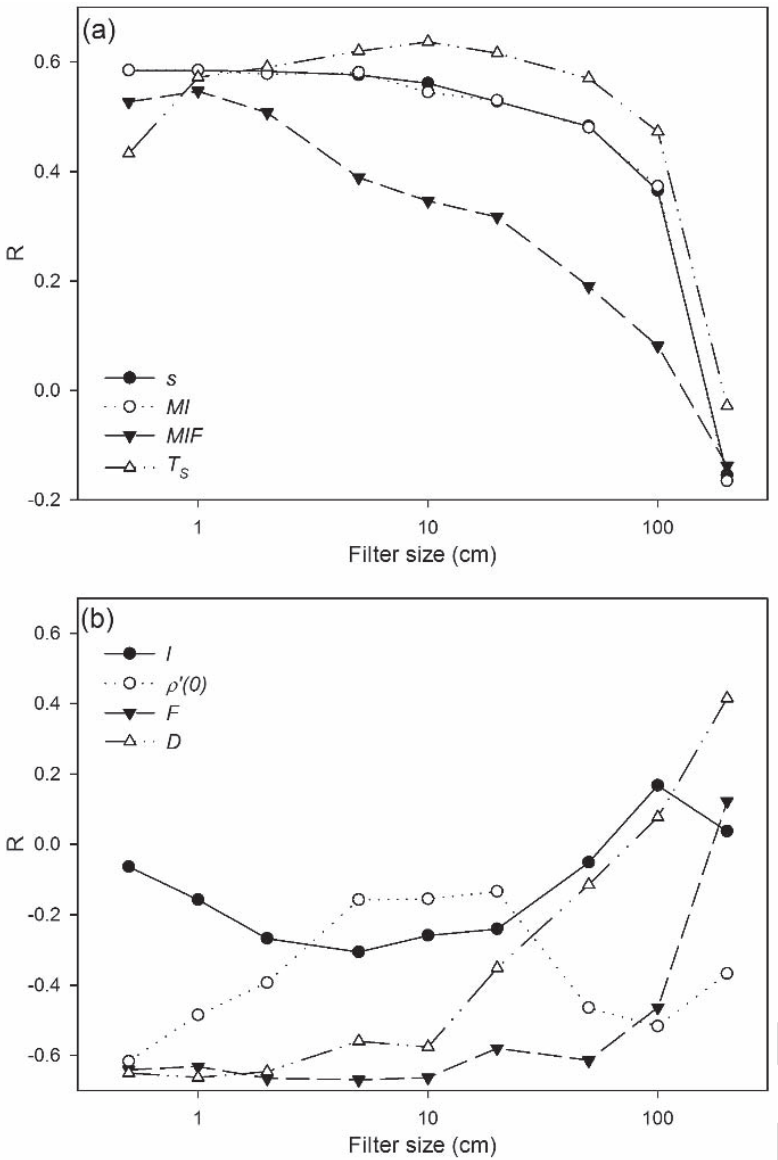

Fig. 11. Influence of profile smoothening on the correlation between $\sigma_{\text {norm }}^{0}$ and the different roughness parameters. The Spearman correlation coefficients $(R)$ are represented for increasing filter sizes. A filter size of $0.5 \mathrm{~cm}$ corresponds to original profiles. (a) Vertical and combined parameters. (b) Horizontal and fractal ones.

the finest roughness components (until 5-cm window size) were discarded. It then peaked at $R \sim-0.35$ and took the opposite trend with $R$ values $\sim 0$ for window sizes longer than $50 \mathrm{~cm}$. On the contrary, $\rho^{\prime}(0)$ had a strongly decreasing correlation as the finest components $(<5 \mathrm{~cm})$ were filtered out but then increased again with filter sizes of $50-100 \mathrm{~cm}$ $(R \sim-0.55)$. Parameter $F$ showed high correlation values $(R \sim-0.6)$ that were insensitive to the removal of high-frequency components until a filter size of $10 \mathrm{~cm}$. After this point, correlation decreased as filter sizes increased. The combined parameter MIF quickly decreased in correlation for increasing filter sizes. In contrast, $T_{S}$ showed a rather insensitive behavior as long as the roughness components below $50 \mathrm{~cm}$ were maintained with maximum correlation values of $R \sim 0.65$ for a filter size of $10 \mathrm{~cm}$. Finally, $D$ had a similar pattern to $F$ with maximum correlation values for profiles that maintained the small-scale roughness components (filter size below $2 \mathrm{~cm}$ ).

The results obtained with the Oh model confirmed the observations above with RMSE values increasing consistently as high-frequency roughness components were removed from the original profiles (i.e., window size increasing in Fig. 12). Smooth classes (i.e., PC and P) were more sensitive than medium or rough classes, and RMSE values increased faster

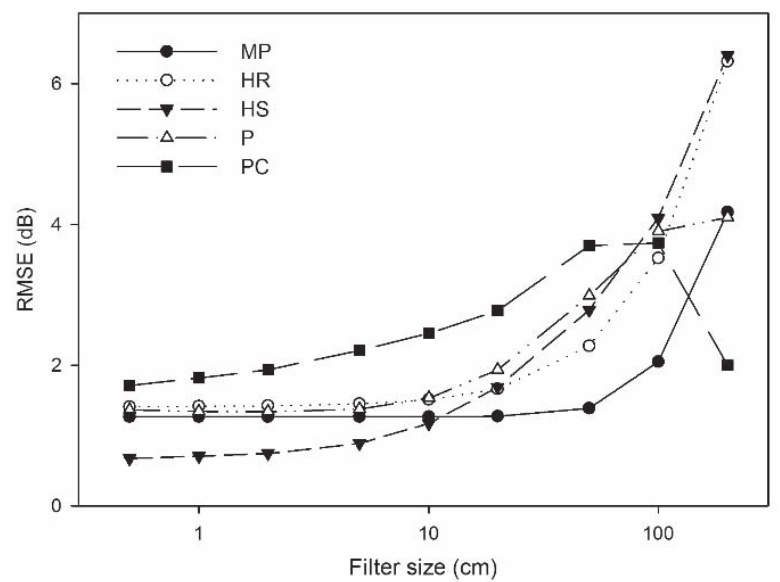

Fig. 12. Roughness class average RMSE between simulated (the Oh model) and observed backscatter values depending on profile smoothening (filter size). A filter size of $0.5 \mathrm{~cm}$ corresponds to original profiles.
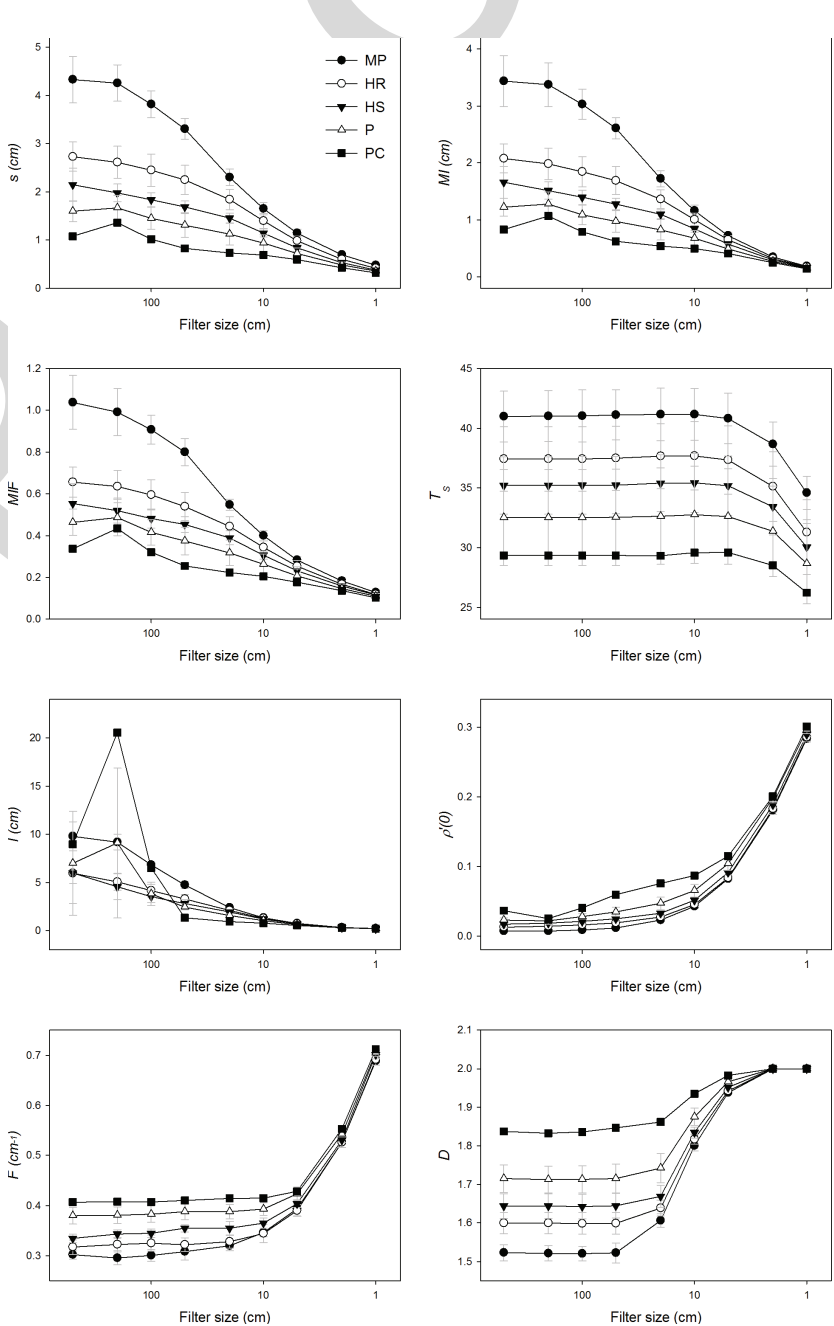

Fig. 13. Influence of high-frequency roughness components on parameter values and standard deviation (error bars) for the different roughness classes for increasing a filter size. Parameter values are computed from profiles obtained as the subtraction of smoothened profiles for increasing filter sizes from the original profiles. A filter size of $500 \mathrm{~cm}$ corresponds to original profiles without filtering.

on the first. Rough classes (in particular MP) were more insensitive and had similar RMSE values until filter sizes of $20-50 \mathrm{~cm}$. 

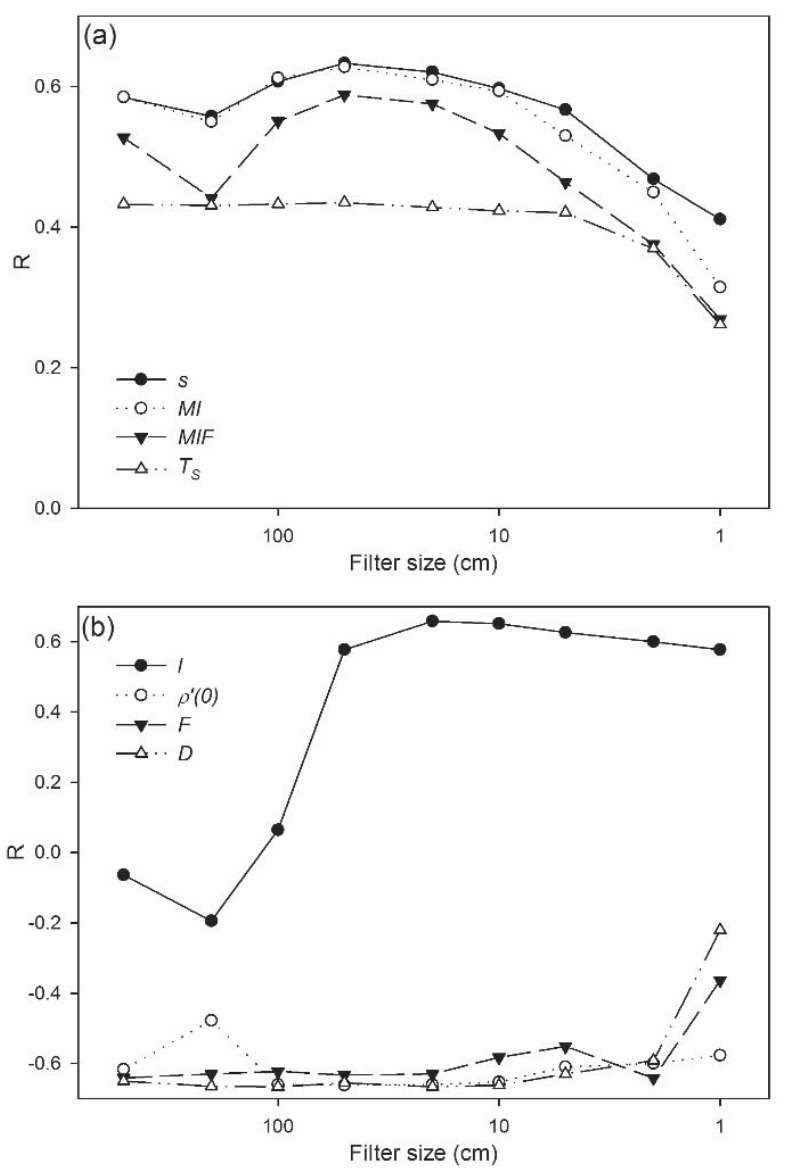

Fig. 14. Influence of high-frequency components on the correlation between $\sigma_{\text {norm }}^{0}$ and the different roughness parameters. Parameter values are computed from profiles obtained as the subtraction of smoothened profiles for increasing a filter size from the original profile. The Spearman correlation coefficients $(R)$ are represented for increasing a filter size. A filter size of $500 \mathrm{~cm}$ corresponds to original profiles without filtering. (a) Vertical and combined parameters. (b) Horizontal and fractal ones.

\section{Influence of High-Frequency Roughness Components}

Most roughness parameters clearly varied when lowfrequency components were subtracted from the roughness profiles. This variation was small when only roughness scale components larger than $1 \mathrm{~m}$ were subtracted (Fig. 13). In turn, when only the shortest components were left (filter window sizes below $10 \mathrm{~cm}$ ), most parameters changed strongly, and the differences between tillage classes were reduced. Parameters $s$, MI, and MIF also had some sensitivity to the removal of the longer roughness components. They showed a linear decay as the frequencies were discarded. The others were quite stable at least until a filter size of $50 \mathrm{~cm}$ [for $\rho^{\prime}(0)$ and $D$ ] or $20 \mathrm{~cm}$ (for $F$ ) was achieved. The $T_{S}$ was quite exceptional, and its values only changed when roughness components shorter than $5 \mathrm{~cm}$ were removed. Finally, $l$ had a decaying trend taking lower values, when longer-frequency components were discarded. However, this general pattern was altered by outliers particularly in smooth classes (PC and P).

Correlation values of vertical parameters with $\sigma_{\text {norm }}^{0}$ decreased when lower-frequency roughness components were subtracted (i.e., shorter filter window size) (Fig. 14). However, the decrease was only noticeable when the filter size was smaller than $\sim 50 \mathrm{~cm}$. Thus, the inclusion of roughness

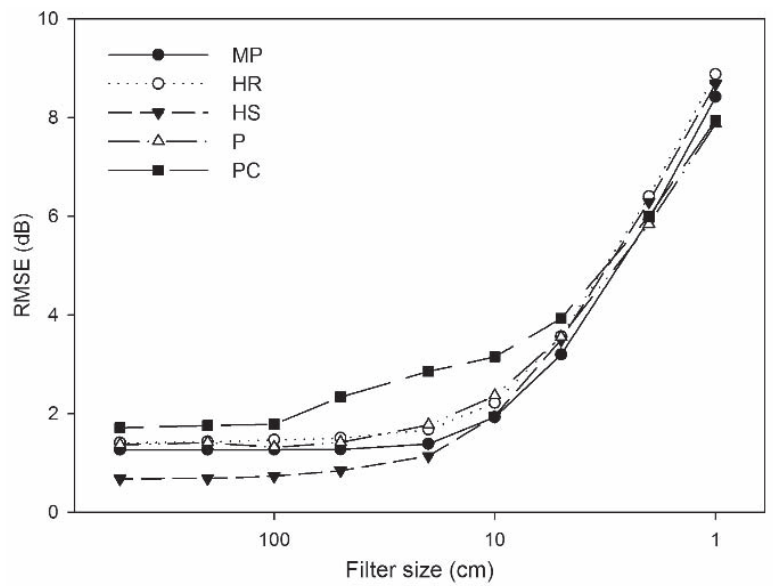

Fig. 15. Influence of high-frequency roughness components on the $\mathrm{Oh}$ model fit. Roughness class average RMSE between simulated and observed backscatter values are represented for increasing a filter size. $s$ values are computed from profiles obtained as the subtraction of smoothened profiles for increasing filter sizes from the original profile. A filter size of $500 \mathrm{~cm}$ corresponds to original profiles without filtering.

frequencies longer than this value did not result in additional enhancements in correlation with $\sigma_{\text {norm. }}^{0}$. Parameters $\rho^{\prime}(0)$, $F$, and $D$ showed a low dependence on the removal of low-frequency components with correlation values decreasing when only scale components smaller than $1 \mathrm{~cm}$ remained. On the other hand, $l$ showed a high sensitivity to roughness components longer than $\sim 50 \mathrm{~cm}$ with correlation values dropping abruptly after this value. It is remarkable that when roughness components longer than $50 \mathrm{~cm}$ were discarded, $l$ had $R$ values $\sim 0.6$, which is similar to those of other horizontal roughness parameters [i.e., $F$ or $\left.\rho^{\prime}(0)\right]$.

The Oh model simulations had a very clear pattern of increasing RMSE when roughness scales below $50 \mathrm{~cm}$ were subtracted (Fig. 15). They rose as high as $8-9 \mathrm{~dB}$ when only components smaller than $1 \mathrm{~cm}$ remained. However, for most classes, the inclusion of roughness components longer than 20 or $50 \mathrm{~cm}$ did not result in additional improvements in RMSE.

Only the smoothest class (PC) seemed to further improve when wavelengths of $100 \mathrm{~cm}$ or longer were included.

\section{Discussion AND CONCLUSION}

The results confirm the clear dependence between roughness measurement scales (i.e., profile lengths) and parameter values. They demonstrate the multiscale behavior of surface roughness, as also observed in [8], [24]-[26], [55], and [56]. Thus, it is necessary to determine which roughness scales are relevant in the backscattering of microwaves over bare soils. Regarding the influence of small-scale components, the results demonstrate that eliminating these small-scale roughness components from the profiles caused a strong variation in the values of horizontal parameters, while vertical ones were more insensitive. This is in agreement with Barber et al. [30] who observed that when the sampling interval increased, $s$ decreased slightly and $l$ increased causing the separability between different roughness classes to decrease. The results also confirm that $l$ values did not stabilize with long profiles, but showed rather an increase in their variability [19], [26]. However, the correlation 
of most parameters with $\sigma_{\text {norm }}^{0}$ and the results obtained with the Oh model did not show great sensitivity to the elimination of these short roughness components until a scale of 2 or $5 \mathrm{~cm}$.

Regarding the influence of large-scale roughness components, previous studies defended the need for long profiles so as to reflect all the roughness components present on a pixel [27], [28] or for a statistically robust estimation of roughness parameters [24]. However, this idea is not in agreement with the rather successful results obtained in studies based on short profiles, i.e., 1-2 m, [32], [57] or in some studies where best results were obtained when roughness parameters were computed after detrending the underlying topographic trend, i.e., removing large-scale roughness [18]. Fung [38] also proposed that meter-size roughness scales did not influence the backscattering process at centimeter-scale wavelengths. The results obtained here illustrate that incorporating roughness scales larger than 1-2 $\mathrm{m}$ to the measurements did not significantly improve the correlation with $\sigma_{\text {norm }}^{0}$ or in the goodness-of-fit of the Oh model simulations. These results support the idea that the low-frequency roughness components do not play an important role in backscattering and also distort different parameter values (especially $l$ ).

Based on these results, it can be suggested that roughness scales between 5 and $50 \mathrm{~cm}$ are the most relevant for C-band backscatter. When the high-frequency roughness components (scales below $5 \mathrm{~cm}$ ) were smoothened, most roughness parameters only slightly decreased their correlation with observed backscatter. Similarly, few differences were observed in the Oh model results when profiles were smoothened up to a filter size of 5-10 cm. Roughness scales larger than 1-2 m might not be relevant in the backscattering of microwaves at C-band. The inclusion of these components in the profile did not provide additional enhancement to the correlation of roughness parameters with backscatter nor in the goodness-offit of the Oh model. In addition, large-scale roughness components had a distorting effect in some roughness parameters especially $l$. With regard to this, it is remarkable that some roughness parameters [i.e., $D, F$, and $\left.\rho^{\prime}(0)\right]$ were more stable and showed a better correlation with backscatter. This could open new possibilities in backscatter modeling. It is important to note that this analysis was based solely on C-band SAR data, and any extrapolation of these results to other frequencies would require new data and analyses.

\section{ACKNOWLEDGMENT}

The authors would like to thank V. R. N. Pauwels for his collaboration for modeling field SM values with TOPLATS.

\section{REFERENCES}

[1] G. Govers, I. Takken, and K. Helming, "Soil roughness and overland flow," Agronomie, vol. 20, no. 2, pp. 131-146, 2000.

[2] L. Zhao, L. Wang, X. Liang, J. Wang, and F. Wu, "Soil surface roughness effects on infiltration process of a cultivated slopes on the loess plateau of China," Water Resour. Manage., vol. 27, no. 14, pp. 4759-4771, 2013.

[3] A. D. Matthias et al., "Surface roughness effects on soil albedo," Soil Sci. Soc. Amer. J., vol. 64, no. 3, pp. 1035-1041, 2000.

[4] J. Cierniewski, C. Kaźmierowski, and S. Królewicz, "Evaluation of the effects of surface roughness on the relationship between soil BRF data and broadband albedo," IEEE J. Sel. Topics Appl. Earth Observ. Remote Sens., vol. 8, no. 4, pp. 1528-1533, Apr. 2015.
[5] K. Helming, M. J. M. Römkens, and S. N. Prasad, "Surface roughness related processes of runoff and soil loss: A flume study," Soil Sci. Soc. Amer. J., vol. 62, no. 1, pp. 243-250, 1998.

[6] J. Vermang, L. D. Norton, C. Huang, W. M. Cornelis, A. M. Da Silva, and D. Gabriels, "Characterization of soil surface roughness effects on runoff and soil erosion rates under simulated rainfall," Soil Sci. Soc. Amer. J., vol. 79, no. 3, pp. 903-916, 2015.

[7] M. W. Smith, "Roughness in the earth sciences," Earth Sci. Rev. vol. 136, pp. 202-225, Sep. 2014.

[8] N. E. C. Verhoest, H. Lievens, W. Wagner, J. Álvarez-Mozos, M. S. Moran, and F. Mattia, "On the soil roughness parameterization problem in soil moisture retrieval of bare surfaces from synthetic aperture radar," Sensors, vol. 8, no. 7, pp. 4213-4248, 2008.

[9] P. Marzahn, D. Rieke-Zapp, and R. Ludwig, "Assessment of soil surface roughness statistics for microwave remote sensing applications using a simple photogrammetric acquisition system," ISPRS J. Photogramm. Remote Sens., vol. 72, pp. 80-89, Aug. 2012.

[10] M. Milenkovic, N. Pfeifer, and P. Glira, "Applying terrestrial laser scanning for soil surface roughness assessment," Remote Sens., vol. 7, no. 2, pp. 2007-2045, 2015.

[11] L. M. Thomsen, J. E. M. Baartman, R. J. Barneveld, T. Starkloff, and J. Stolte, "Soil surface roughness: Comparing old and new measuring methods and application in a soil erosion model," Soil, vol. 1, no. 1, pp. 399-410, 2015

[12] A. Martinez-Agirre, J. Álvarez-Mozos, and R. Giménez, "Evaluation of surface roughness parameters in agricultural soils with different tillage conditions using a laser profile meter," Soil Tillage Res., vol. 161, pp. 19-30, Aug. 2016.

[13] A. K. Fung, Microwave Scattering and Emission Models and Their Applications. Norwell, MA, USA: Artech House, 1994.

[14] F. T. Ulaby, P. C. Dubois, and J. van Zyl, "Radar mapping of surface soil moisture," J. Hydrol., vol. 184, nos. 1-2, pp. 57-84, 1996.

[15] W. Wagner et al., "Operational readiness of microwave remote sensing of soil moisture for hydrologic applications," Hydrol. Res., vol. 38, no. 1, pp. 1-20, 2007.

[16] P. Dobriyal, A. Qureshi, R. Badola, and S. A. Hussain, "A review of the methods available for estimating soil moisture and its implications for water resource management," J. Hydrol., vols. 458-459, pp. 110-117, Aug. 2012.

[17] K. C. Kornelsen and P. Coulibaly, "Advances in soil moisture retrieval from synthetic aperture radar and hydrological applications," J. Hydrol., vol. 476, pp. 460-489, Jan. 2013.

[18] R. Bryant et al., "Measuring surface roughness height to parameterize radar backscatter models for retrieval of surface soil moisture," IEEE Geosci. Remote Sens. Lett., vol. 4, no. 1, pp. 137-141, Jan. 2007.

[19] H. Lievens, H. Vernieuwe, J. Álvarez-Mozos, B. De Baets, and N. E. C. Verhoest, "Error in radar-derived soil moisture due to roughness parameterization: An analysis based on synthetical surface profiles," Sensors, vol. 9, no. 2, pp. 1067-1093, 2009.

[20] F. T. Ulaby, R. K. Moore, and A. K. Fung, "Microwave remote sensing: Active and passive," Radar Remote Sensing and Surface Scattering and Emission Theory (Remote Sensing Series), vol 3. Reading, MA, USA: Addison-Wesley, 1982.

[21] A. K. Fung, Z. Li, and K. S. Chen, "Backscattering from a randomly rough dielectric surface," IEEE Trans. Geosci. Remote Sens., vol. 30, no. 2, pp. 356-369, Mar. 1992.

[22] Y. Oh, K. Sarabandi, and F. T. Ulaby, "An empirical model and an inversion technique for radar scattering from bare soil surfaces," IEEE Trans. Geosci. Remote Sens., vol. 30, no. 2, pp. 370-381, Mar. 1992.

[23] P. C. Dubois, J. V. Zyl, and T. Engman, "Measuring soil moisture with imaging radars," IEEE Trans. Geosci. Remote Sens., vol. 33, no. 4, pp. 915-926, Jul. 1995

[24] Y. Oh and Y. C. Kay, "Condition for precise measurement of soil surface roughness," IEEE Trans. Geosci. Remote Sens., vol. 36, no. 2, pp. 691-695, Mar. 1998.

[25] F. Mattia et al., "A comparison between soil roughness statistics used in surface scattering models derived from mechanical and laser profilers," IEEE Trans. Geosci. Remote Sens., vol. 41, no. 7, pp. 1659-1671, Jul. 2003.

[26] M. Callens, N. E. C. Verhoest, and M. W. J. Davidson, "Parameterization of tillage-induced single-scale soil roughness from 4-m profiles," IEEE Trans. Geosci. Remote Sens., vol. 44, no. 4, pp. 878-887, Apr. 2006.

[27] M. W. J. Davidson, T. L. Toan, F. Mattia, G. Satalino, T. Manninen, and M. Borgeaud, "On the characterization of agricultural soil roughness for radar remote sensing studies," IEEE Trans. Geosci. Remote Sens., vol. 38, no. 2, pp. 630-640, Mar. 2000. 
[28] A. T. Manninen, "Multiscale surface roughness description for scattering modelling of bare soil," Phys. A, Statist. Mech. Appl., vol. 319, pp. 535-551, Apr. 2003.

[29] European Spatial Agency. (2016). EO Portal Directory, Satellite Missions Database. [Online]. Available: http://directory. oeportal.org/web/eoportal/satellite-missions

[30] M. E. Barber, F. M. Grings, J. Álvarez-Mozos, M. Piscitelli, P. A. Perna, and H. Karszenbaum, "Effects of spatial sampling interval on roughness parameters and microwave backscatter over agricultural soil surfaces," Remote Sens., vol. 8, no. 6, p. 458, 2016.

[31] Z. Su, P. A. Troch, and F. P. De Troch, "Remote sensing of bare surface soil moisture using EMAC/ESAR data," Int. J. Remote Sens., vol. 18, no. 10 , pp. 2105-2124, 1997.

[32] N. Baghdadi, N. Holah, and M. Zribi, "Calibration of the integral equation model for SAR data in C-band and HH and VV polarizations," Int. J. Remote Sens., vol. 27, no. 4, pp. 805-816, 2006.

33] A. T. Joseph, R. van der Velde, P. E. O’Neill, R. H. Lang, and T. Gish, "Soil moisture retrieval during a corn growth cycle using L-band (1.6 GHz) radar observations," IEEE Trans. Geosci. Remote Sens., vol. 46, no. 8, pp. 2365-2374, Aug. 2008.

[34] H. Lievens et al., "Effective roughness modelling as a tool for soil moisture retrieval from C- and L-band SAR," Hydrol. Earth Syst. Sci., vol. 15, no. 1, pp. 151-162, 2011.

[35] L. Dong, N. Baghdadi, and R. Ludwig, "Validation of the AIEM through correlation length parameterization at field scale using radar imagery in a semi-arid environment," IEEE Geosci. Remote Sens. Lett., vol. 10, no. 3, pp. 461-465, May 2013.

[36] N. Baghdadi et al., "Semi-empirical calibration of the Integral Equation Model for co-polarized L-band backscattering," Remote Sens., vol. 7, no. 10, pp. 13626-13640, 2015.

[37] X. Bai, B. He, and X. Li, "Optimum surface roughness to parameterize advanced integral equation model for soil moisture retrieval in prairie area using Radarsat-2 data," IEEE Trans. Geosci. Remote Sens., vol. 54, no. 4, pp. 2437-2449, Apr. 2016.

[38] A. K. Fung, Backscattering From Multiscale Rough Surfaces With Application to Wind Scatterometry. Norwood, MA, USA: Artech House, 2015.

[39] J. Casalí et al., "Runoff, erosion, and water quality of agricultural watersheds in central Navarre (Spain)," Agricult. Water Manage., vol. 95, no. 10, pp. 1111-1128, 2008.

[40] J. Álvarez-Mozos, N. E. C. Verhoest, A. Larrañaga, J. Casalí, and M. González-Audícana, "Influence of surface roughness spatial variability and temporal dynamics on the retrieval of soil moisture from SAR observations," Sensors, vol. 9, no. 1, pp. 463-489, 2009.

[41] T. M. Zobeck and C. A. Onstad, "Tillage and rainfall effects on random roughness: A review," Soil Tillage Res., vol. 9, pp. 1-20, Jan. 1987.

[42] J. E. Gilley and E. R. Kootwitz, "Random roughness assessment by the pin and chain method," Appl. Eng. Agricult., vol. 12, no. 1, pp. 39-43, 1995.

[43] J. S. Famiglietti and E. F. Wood, "Multiscale modeling of spatially variable water and energy balance processes," Water Resour. Res., vol. 30, no. 11, pp. 3061-3078, 1994.

[44] V. R. N. Pauwels, R. Hoeben, N. E. C. Verhoest, and F. P. De Troch, "The importance of the spatial patterns of remotely sensed soil moisture in the improvement of discharge predictions for small-scale basins through data assimilation," J. Hydrol., vol. 251, nos. 1-2, pp. 88-102, 2001.

[45] R. R. Allmaras, R. E. Burwell, W. E. Larson, W. W. Nelson, and R. F. Holt, "Total porosity and random roughness of the interrow zone as influenced by tillage," ARS-USDA, Washington, DC, USA, Tech. Rep. 7, 1966.

[46] M. J. M. Romkens and J. Y. Wang, "Effect of tillage on surface roughness," Trans. AsAE, vol. 29, no. 2, pp. 429-433, 1986.

[47] A. Saleh, "Soil roughness measurement: Chain method," J. Soil Water Conservation, vol. 48, no. 6, pp. 527-529, 1993.

[48] E. V. Vázquez, J. G. V. Miranda, and A. P. González, "Characterizing anisotropy and heterogeneity of soil surface microtopography using fractal models," Ecol. Model., vol. 182, nos. 3-4, pp. 337-353, 2005.

[49] M. Abdel-Messeh and S. Quegan, "Variability in ERS scatterometer measurements over land," IEEE Trans. Geosci. Remote Sens., vol. 38, no. 4, pp. 1767-1776, Jul. 2000.

[50] S. L. Hegarat-Mascle, M. Zribi, F. Alem, A. Weisse, and C. Loumagne, "Soil moisture estimation from ERS/SAR data: Toward an operational methodology," IEEE Trans. Geosci. Remote Sens., vol. 40, no. 12, pp. 2647-2658, Dec. 2002.

[51] D. P. Thoma et al., "Comparison of four models to determine surface soil moisture from C-band radar imagery in a sparsely vegetated semiarid landscape," Water Resour. Res., vol. 42, no. 1, 2006, Art. no. W01418.
[52] N. Baghdadi and M. Zribi, "Evaluation of radar backscatter models IEM, $\mathrm{OH}$ and Dubois using experimental observations," Int. J. Remote Sens., vol. 27, no. 18, pp. 3831-3852, 2006.

[53] R. Panciera, M. A. Tanase, K. Lowell, and J. P. Walker, "Evaluation of IEM, Dubois, and Oh radar backscatter models using airborne L-band SAR," IEEE Trans. Geosci. Remote Sens., vol. 52, no. 8, pp. 4966-4979, Aug. 2014.

[54] P. Beckmann and A. Spizzichino, The Scattering of Electromagnetic Waves From Rough Surfaces. Norwood, MA, USA: Artech House, 1987.

[55] L. Zhixiong, C. Nan, U. D. Perdok, and W. B. Hoogmoed, "Characterisation of soil profile roughness," Biosyst. Eng., vol. 91, no. 3, pp. 369-377, 2005.

[56] B. Snapir, S. Hobbs, and T. W. Waine, "Roughness measurements over an agricultural soil surface with Structure from Motion," ISPRS J. Photogramm. Remote Sens., vol. 96, pp. 210-223, Oct. 2014

[57] M. W. J. Davidson et al., "Joint statistical properties of RMS height and correlation length derived from multisite 1-m roughness measurements,' IEEE Trans. Geosci. Remote Sens., vol. 41, no. 7, pp. 1651-1658, Jul. 2003.

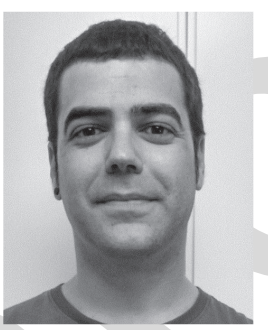

Alex Martinez-Agirre received the B.S. degree in surveying technical engineering from the University of the Basque Country, Vitoria-Gasteiz, Spain, in 2006, and the M.S. degree in geodesy and cartography engineering from the University of Alcalá, Alcalá de Henares, Spain, in 2009. His $\mathrm{Ph} . \mathrm{D}$. thesis focused on surface roughness on agricultural soils measured by in situ and remote sensing techniques.

He is currently a Research Fellow with the Department of Projects and Rural Engineering, Public University of Navarre, Pamplona, Spain.

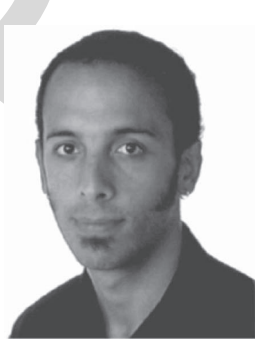

Jesús Álvarez-Mozos received the Engineering and $\mathrm{Ph} . \mathrm{D}$. degrees in agricultural engineering from the Public University of Navarre, Pamplona, Spain, in 2001 and 2006, respectively.

He was a Teaching Assistant from 2001 to 2010 with the Department of Projects and Rural Engineering, Public University of Navarre, where he was appointed Associate Professor in 2010. His research interests include remote sensing data processing and hydrological and agricultural applications of remote sensing.

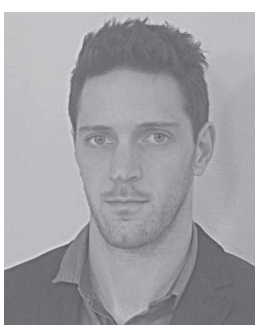

Hans Lievens received the Engineering and Ph.D. degrees in applied biological sciences from Ghent University, Ghent, Belgium, in 2007 and 2011, respectively.

Since 2011, he has been a Post-Doctoral Research Fellow with the Research Foundation Flanders (FWO), Ghent University. In 2016, he joined the Global Modeling and Assimilation Office, NASA Goddard Space Flight Center, Greenbelt, MD, USA, as a Visiting Scientist. His research interests include soil moisture retrieval from active and passive microwave remote sensing, hydrologic modeling, and data assimilation.

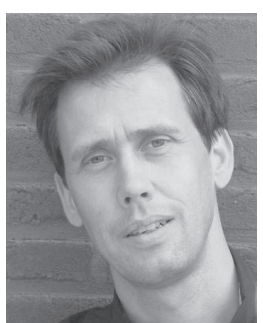

Niko E. C. Verhoest received the Engineering and Ph.D. degrees in applied biological sciences from Ghent University, Ghent, Belgium, in 1994 and 2000, respectively.

He was a Teaching Assistant from 1998 to 2000 and an Assistant Professor from 2000 to 2002 with the Laboratory of Hydrology and Water Management, Ghent University, where he became an Associate Professor of Hydrology and Water Management with the Faculty of Bioscience Engineering, in 2002. His research interests include the hydrological applications of radar remote sensing. 